\title{
Impacto econômico do uso racional de papel nas avaliações de uma escola em Barueri, SP
}

Economic impact of the rational use of paper in the evaluations of a school in Barueri, SP

\author{
André Luís Fernandes dos Santos ${ }^{1 *}$, Roberta Leopoldo Ferreira ${ }^{2}$
}

1*Fundação Instituto de Educação de Barueri (FIEB) - Professor - Rua do ITB do Engenho Novo, 238 - 06415-080 - Barueri, SP - Brasil <andrvet@usp.br>

${ }^{2}$ Escola Superior de Agricultura Luiz Queiroz da Universidade de São Paulo - Doutora em Ciências - Av. Pádua Dias, n 11 - $13418-900$ - Piracicaba, SP - Brasil

\section{Resumo}

As instituições de ensino são grandes consumidoras de papéis em suas atividades. Há o interesse das escolas em diminuir o seu uso, devido às questões ambientais e econômicas, pois o desperdício é oneroso. Uma das estratégias para a redução no uso é realizar mudanças na formatação e impressão dos documentos. $\mathrm{O}$ objetivo desse trabalho foi analisar o impacto econômico no uso de papel sulfite nas avaliações trimestrais e semestrais, com a obrigatoriedade da impressão frente e verso e formatação padrão (fonte Times New Roman 12 e texto em duas colunas), em uma instituição de ensino pública no município de Barueri, estado de São Paulo. Com essa obrigatoriedade, houve uma economia de 17.536 sulfites e com isso a instituição economizou R\$1.363,86, portanto houve diminuição no custo de 55,85\% quando comparada à impressão apenas em uma face do papel. A economia gerada possibilitou a implantação de cartões para a correção das avaliações, sem nenhum custo para a instituição, por 2,3 anos letivos. Uma simples mudança na forma da impressão, que depende apenas do uso da impressora e de um trabalho de conscientização dos educadores da instituição, trouxe benefícios econômicos. Além dos impactos econômicos e educacionais, o modelo de impressão adotado alinha a instituição às preocupações ambientais atuais.

Palavras-chave: avaliação escolar, gestão escolar, papel sulfite, sustentabilidade

\begin{abstract}
The educational institutions are major consumers of papers in their activities. There is the interest of the schools in reducing its use, due to the environmental and economic issues, because the waste is costly. One of the strategies for the reduction in the use is to make changes in the formatting and printing of documents. The objective of this study was to analyze the economic impact of the use of sulphite paper in the quarterly and semi-annual evaluations, with the requirement of front and back printing and standard formatting (Times New Roman 12 font and text in two columns) in a public educational institution in Barueri-SP. With this obligation there was an economy of 17,536 sulphite papers and with that the institution saved R \$ $1,363.86$, thus there was a decrease in the cost of $55.85 \%$ when compared to the printing on only one side of the paper. The savings generated allowed the implementation of cards for the correction of the evaluations, at no cost to the institution, for 2.3 academic years. A simple change in the form of printing, which depends only on the use of the printer and the work of educating the institution's educators, has brought economic benefits. In addition to the economic and educational impacts, the adopted print model aligns the institution with current environmental issues.
\end{abstract}

Keywords: school evaluation, school management, sulphite paper, sustainability

\section{Introdução}

O papel é um dos produtos mais consumidos no Brasil e no mundo, inclusive nas atividades educacionais e administrativas. Na administração pública é um dos principais recursos naturais consumidos, em especial o papel sulfite A4 (Dias, 2013). Nos últimos 30 anos, o seu consumo aumentou em 50\%, fato incompreensível em uma sociedade onde sustentabilidade tem sido propalada (The Economist, 2012). Porém, esse aumento pode ser explicado pela burocracia, que se caracteriza pela existência de enorme quantidade de documentos e um excesso de rotinas de trabalho e, consequentemente, o acúmulo de papéis; isso demanda em grandes espaços para o armazenamento dos documentos físicos gerados e altos investimentos para aquisição de sulfite tamanho A4 (Siqueira et al., 2018).

As instituições de ensino, em suas rotinas burocrática e pedagógica, são grandes consumidoras de papéis, de tipos variados. Há o interesse nos gestores e comunidade escolar em diminuir o seu uso, devido às questões 
ambientais e econômicas pois, o desperdício de papel é oneroso. Por isso, é desejável instituir o uso racional do papel, em especial do papel sulfite (Dias, 2013). A questão ambiental é relevante pois, para se produzir uma tonelada de papel são necessários, aproximadamente, a derrubada de 20 eucaliptos e sua produção industrial é feita pelo processo Kraft, que produz resíduos altamente poluidores, como compostos clorados (Castro, 2009; Grande, 2012 ${ }^{1}$ ).

Uma das estratégias para a diminuição do consumo papeleiro é realizar mudanças na formatação e impressão dos documentos, como sua revisão na tela do computador; redução nas margens das páginas, especialmente em documentos com grande número de páginas, utilizando margens com $0,5 \mathrm{~cm}$, por exemplo; priorização de fontes menores no momento da digitação e utilização da opção de impressão frente e verso, para o uso integral do papel (Teixeira, 2007).

O objetivo desse trabalho foi analisar a economia de papel sulfite e seu impacto econômico em uma instituição de ensino no município de Barueri-SP, após a implantação de uma semana de avaliações trimestrais e semestrais com a obrigatoriedade da formatação e impressão padrão determinada pela equipe de gestão escolar.

\section{Material e Métodos}

As informações sobre o sistema de avaliação da unidade escolar foram cedidas pela equipe gestora no mês de março de 2017. A unidade possui quatro cursos de formação técnica (Análises Clínicas, Enfermagem, Farmácia, Informática para Internet e Química), com aulas nos períodos matutino, vespertino e noturno.

Os cursos são oferecidos nas modalidades integrada, concomitante e subsequente. Para facilitar a nomenclatura na administração escolar os alunos são divididos em dois grandes grupos: o integrado, com curso de três anos de duração, nos períodos matutino e vespertino e o módulo, que inclui discentes da modalidade concomitante e subsequente, com duração de três semestres, no período noturno.

Os alunos dos dois grupos devem realizar, pelo menos, três avaliações obrigatórias e duas continuadas (monografias, seminários ou trabalhos em grupo). Para os alunos do integrado, uma das avaliações obrigatórias, denominadas trimestrais e para os alunos do módulo, as semestrais; nessas avaliações houve o envolvimento de toda a comunidade escolar pois, os educandos realizaram as avaliações das disciplinas em uma semana reservada no calendário escolar.

A formatação e impressão padrão para a elaboração dessas avaliações foi feita na fonte Times New Roman 12 e texto em duas colunas. A formatação foi determinada pela gestão escolar da unidade, com a preocupação prioritária de economia de papel e, consequentemente, de recurso financeiro. A impressão deveria utilizar a frente e o verso da folha sulfite tamanho A4. O número de questões por disciplina seguiu ao seguinte critério: disciplinas com uma aula semanal (cinco questões); com duas aulas (10 questões); com três ou mais aulas (15 questões).

Para o cálculo aproximado do uso de sulfite foi consultado o banco de arquivos de avaliações trimestrais e semestrais da unidade escolar, que reuniu as avaliações de todas as disciplinas e cursos. Além disso, considerouse também o número de alunos por classe e curso. A partir da análise dos dados anteriormente citado, verificou-se que as avaliações com cinco e 10 questões utilizaram uma sulfite apenas, as avaliações com 15 questões utilizaram duas folhas de sulfite. Esse cálculo aproximado considerou as avaliações realizadas dentro da formatação oficial.

O valor pago, em reais, por pacote de 500 folhas de sulfite tamanho A4 foi obtido com coordenador de compras e licitação da mantenedora da unidade escolar estudada. Para a obtenção dos valores, em reais, das sulfites adquiridas no varejo foi feita uma pesquisa na internet. A pesquisa foi realizada em lojas especializadas na comercialização de artigos para escritórios, em três estabelecimentos diferentes. Foram cotadas cinco marcas comerciais (embalagens com 500 folhas) para o estabelecimento de um preço médio. Essa pesquisa do valor do sulfite no varejo foi feita para estimar a economia gerada na compra de grandes volumes, comuns nas licitações.

Outros detalhes das avaliações trimestrais e semestrais foi que as mesmas foram corrigidas pela leitura de um cartão, preenchido pelos alunos, semelhante aos utilizados nos concursos públicos e vestibulares. Durante toda a semana de avaliações, foram utilizados quatro cartões por aluno. O valor, em reais, dos cartões foi fornecido pela gestão escolar da unidade. A questão do uso dos cartões fez parte desse trabalho, pois os mesmos, a priori, onerariam a instituição; porém, os gestores acreditaram que a economia gerada pela formatação e impressão oficial seria suficiente para cobrir o custo desses cartões.

Para os cálculos foi utilizada a estatística descritiva e os dados foram apresentados em tabelas e gráficos, para melhor comparação entre consumo de papel nos dois tipos de impressão (frente, frente e verso) e economia, em reais, gerada pela formatação e impressão padrão em cada trimestre e semestre; e, consequentemente, no período de um ano.

${ }^{1}$ Grande, J.P. 2012. Dimensões de cavacos industriais de eucalipto e relações compolpação, resistência e morfologia de fibras de polpa. Dissertação de Mestrado em Ciência Florestal. Universidade Estadual Paulista, Botucatu, SP. Brasil. 


\section{Resultados e Discussão}

A instituição de ensino estudada pública e municipal, com 1.398 alunos, do total 375 (26,8\%) estudaram no período matutino, $543(38,8 \%)$ no vespertino e 480 $(34,9 \%)$ no noturno. Logo, 65,6\% pertenceram ao integrado e os demais ao módulo.

Os educandos do integrado consumiram 16.830 sulfites com a impressão padrão da avaliação trimestral. Se as avaliações fossem impressas apenas no anverso da folha, o consumo seria de 28.091 sulfites; a economia com a impressão padrão foi de 11.261 unidades. No módulo, nas avaliações semestrais, o consumo foi de 5.993 e 9.222 sulfites respeitando-se a impressão padronizada e quando utilizou apenas a frente do papel, respectivamente. Portanto, houve uma economia de 3.229 sulfites. O consumo total de sulfites, no integrado e módulo, foi de 22.823 e 40.359 sulfites na impressão padronizada e utilizando-se apenas o anverso, respectivamente. $O$ resultado foi uma economia de 17.536 sulfites (Figura 1).

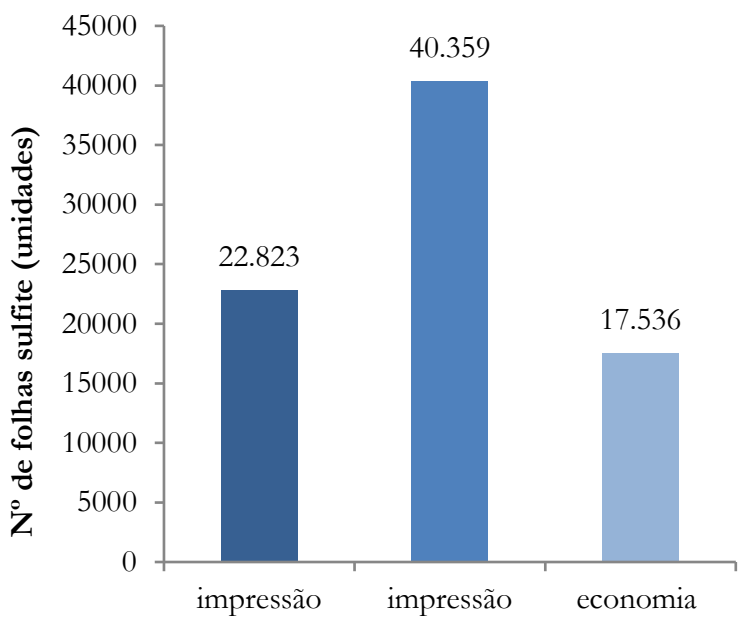

Figura 1. Consumo folhas de sulfite, em unidades, nas modalidades de impressão e a economia utilizando a impressão padrão

O papel foi adquirido pela mantenedora por processo licitatório, conforme o artigo 37 da Constituição Federal (Brasil, 1988). Para a compra foi realizado um Pregão presencial, associado à Ata de Registro de Preços [ARP]; o pacote de sulfite de 500 folhas foi adquirido por R $\$$ 13,80 .

Na Tabela 1 estão os resultados da economia de papel nos dois grupos, de acordo com a formatação e impressão em um ano. A economia de papel sulfite foi de 42.921 e 6.458 folhas para os cursos da modalidade integrada e modular, respectivamente. Esta economia somada resultou em 49.379 sulfites, o que representou uma economia de 98,76 de pacotes de 500 folhas. A economia, em reais, foi de $\mathrm{R} \$ 1.363,86$. Em termos percentuais, a impressão padrão gerou uma economia de 55,85\% em relação a impressão utilizando apenas a frente da sulfite.

Tabela 1. Economia gerada, em reais, pela impressão padrão no período de um ano letivo

\begin{tabular}{lcrrr}
\hline \multirow{2}{*}{ Grupos } & \multicolumn{2}{c}{ Total de sulfites por ano } & \multicolumn{2}{c}{ Economia } \\
\cline { 2 - 6 } & $\begin{array}{c}\text { Impressão } \\
\text { padrão }\end{array}$ & Frente & Unidade & Pacotes \\
\hline & -------------- unidades & -------------- \\
Integrado & $50.490,00$ & $93.411,00$ & $42.921,00$ & 85,84 \\
Módulo & $11.986,00$ & $18.444,00$ & $6.458,00$ & 12,92 \\
\hline Custo $(\mathrm{R} \$)$ & $1.724,34$ & $3.087,20$ & $1.363,86$ & \\
\hline
\end{tabular}

O consumo total de cartões utilizados nas semanas de avaliações trimestrais foi de 5.592 unidades e o custo dos cartões foi de $\mathrm{R} \$ 575,98$. Com a economia, em reais, gerada pela impressão padrão em um ano letivo, pode-se adquirir cartões para serem usados por, aproximadamente, 2,3 anos letivos (Tabela 2).

Tabela 2. Custo dos cartões, em reais, por grupo (integrado e módulo)

\begin{tabular}{lcrr}
\hline Grupo & \multicolumn{1}{c}{ Alunos } & \multicolumn{1}{c}{ Cartões } & \multicolumn{1}{c}{ Custo } \\
\hline & ----------- unidade & ---------- & -- \\
Integrado & 918 & 3.672 & 378,22 \\
Módulo & 480 & 1.920 & 197,76 \\
\hline Total & 1.398 & 5.592 & 575,98 \\
\hline
\end{tabular}

$\mathrm{Na}$ instituição, o consumo de papel foi concentrado na secretaria escolar, na elaboração de diversos documentos, como os certificados e outros relacionados à gestão escolar. Na secretaria houve um forte incentivo ao consumo consciente de papel, com a confecção de blocos de anotação com as sulfites que seriam descartadas e reciclagem da mesma na impossibilidade do reuso.

Sabe-se que o papel é amplamente utilizado em todos os setores da sociedade e os estabelecimentos educacionais são um dos grandes consumidores deste recurso. Nesses locais há um uso excessivo de papel para imprimir documentos, ofícios, certificados, processos, protocolos, entre outros, estando os mesmos sujeitos a desperdício (Tauchen; Brandli, 2006).

A preocupação da gestão escolar foi, em um primeiro momento, com as questões de custo. Apesar disso, o uso racional do papel e sustentável do papel é coerente com o artigo 225 da Constituição Federal (Brasil, 1988), que assegura aos brasileiros um meio ambiente ecologicamente equilibrado e determina que o Estado, 
em todas as suas instâncias, cumpra a sua função de atender simultaneamente o aproveitamento racional dos recursos naturais e a preservação do meio ambiente (Teixeira et al., 2015).

No futuro, a instituição pode utilizar também o princípio do 3R (reduzir, reutilizar e reciclar), que foi um dos resultados obtidos nos debates do ECO-92, para a solução ou redução nos transtornos relacionados ao acúmulo de resíduos sólidos, onde cada " $\mathrm{R}$ ” representa uma mudança no comportamento de consumo (reduzir, reutilizar e reciclar) (Bortolozzi, 2002). Há ainda o chamado conceito do $5 \mathrm{R}$, onde adiciona-se ao $3 \mathrm{R}$ os conceitos de repensar o uso dos recursos naturais e recusar práticas não sustentáveis (Seduc-MT, 2009).

A reciclagem do papel é de suma importância ambiental e econômica. Estimou que reduza em 74\% e 35\% poluição do ar e das águas, respectivamente. Somado a isso, a reciclagem decresceu o uso energético da indústria de papel e celulose, pois estimou que reciclagem 500 mil toneladas de papel corresponderam a uma economia energética equivalente a 40 mil toneladas de petróleo (Castro, 2009).

Em relação às avaliações trimestrais e semestrais a preocupação da gestão foi grande, pois as mesmas demandaram uma quantidade enorme de sulfites tamanho A4 em um curto intervalo de tempo e envolveu dezenas de docentes. O fato de muitos docentes estarem envolvidos poderia gerar uma diversidade enorme nas formatações das avaliações. Por isso, foi necessária a padronização da formatação e impressão das mesmas, sendo que a impressão frente e verso foi a normatização que mais impactou na economia de papel. Este fato também observado em uma instituição de ensino superior em Alfenas, MG, onde foi observada a relação direta entre consumo exagerado de papel e poucas impressões utilizando o verso do sulfite, fato que gerava maior custo financeiro à instituição, que decidiu implantar medidas para evitar o desperdício (Mendes et al., 2013).

A compra de um grande número de pacotes de sulfite possibilitou à instituição negociar valores abaixo dos cobrados no varejo. O preço médio obtido pela mantenedora da escola estudada, após processo licitatório, foi de $\mathrm{R} \$ 13,80$ por pacote de 500 folhas, fato comprovado em uma universidade em Alfenas, MG que conseguiu, no ano de 2012, obter um valor de $\mathrm{R} \$ 8,63$ por pacote, em uma compra de 30.809 pacotes (Mendes et al., 2013). Em relação aos custos do papel sulfite no varejo, foram pesquisadas cinco marcas comerciais diferentes, em três importantes lojas do ramo, denominadas de locais 1, 2 e 3 . O custo médio, em reais, do pacote com 500 folhas de sulfite nos diferentes locais foi de $\mathrm{R} \$ 19,63 ; \mathrm{R} \$ 20,29 ; \mathrm{R} \$ 19,29 ; \mathrm{R} \$ 22,63 ; \mathrm{R} \$ 21,97$, para as marcas A, B, C, D e E, respectivamente. Para os cálculos utilizou-se a média desses valores que foi de $\mathrm{R} \$ 20,76$ por pacote (Tabela 3). Portanto, a estratégia da mantenedora foi acertada, pois gerou uma economia, em média, de R\$ 6,96.

Tabela 3. Valor médio, em reais, do pacote de 500 folhas sulfites tamanho A4, de cinco diferentes marcas

\section{inco diferentes marcas}

\begin{tabular}{|c|c|c|c|c|}
\hline $\begin{array}{c}\text { Marca do } \\
\text { sulfite }\end{array}$ & Local 1 & Local 2 & Local 3 & Média \\
\hline & \multicolumn{4}{|c|}{ - } \\
\hline A & 21,90 & 19,99 & 16,99 & 19,63 \\
\hline B & 21,90 & 18,99 & 19,99 & 20,29 \\
\hline $\mathrm{C}$ & 21,90 & 16,99 & 18,99 & 19,29 \\
\hline $\mathrm{D}$ & 30,00 & 18,90 & 18,99 & 22,63 \\
\hline $\mathrm{E}$ & 29,10 & 17,90 & 18,90 & 21,97 \\
\hline
\end{tabular}

Moraes et al. (2011) observou que o consumo de papéis destinados a impressão teve aumento em seu uso, justamente no momento em que os investimentos em tecnologia da informação eram altos. Os autores entenderam que o fácil acesso a equipamentos de informática, incluindo impressoras, levaria a impressão de arquivos eletrônicos, porém o uso de papel para a escrita diminuiu com o avanço tecnológico, pois foi possível escrever e armazenar textos no computador, sem a necessidade de impressão. Devido a esse fato, a escola pode optar em substituir as avaliações trimestrais e semestrais impressas por avaliações eletrônicas, que teriam como vantagem não utilizar papel e ter correção informatizada, dispensando o uso dos cartões (que também utilizam papel na sua produção).

A relação informática e economia papeleira foi observada por Siqueira et al. (2018), que realizou um estudo sobre o processo de consulta de pontos nas carteiras de habilitação $[\mathrm{CNH}]$ dos condutores no estado de São Paulo e percebeu que esse processo possuía, antes da informatização, muitas etapas, entre elas o preenchimento e impressão do requerimento acompanhado de cópia da CNH. Com a introdução do site para consulta de pontuação não houve mais a necessidade da impressão de qualquer documento e nos anos de 2016 e 2017 (16 meses no total) foram economizadas 10 milhões de sulfites tamanho A4. Sobre o uso de internet, Bonifácio; Fiorini e Garcia (2016) indagaram os estudantes de uma instituição de ensino superior [IES] sobre as sugestões que dariam para a economia de sulfite na instituição e $41 \%$ deles responderam que a IES deveria fornecer o material de apoio aos cursos oferecidos on line, ao invés de cópias impressas. 
As questões levantadas com a mudança na formatação e impressão das avaliações trimestrais e semestrais, que visavam em um primeiro momento uma economia monetária, poderiam ser utilizadas para um trabalho de conscientização ambiental, estimulando os alunos para utilizarem todas as folhas do seu caderno, dar preferência ao uso de produtos feitos com papel reciclado, ou seja, habituarem-se a praticar os princípios do 5R. Andreotti (2014), em seu estudo observou que após a conscientização no uso do papel, focada nos alunos do nono ano do ensino fundamental e do ensino médio, resultou em uma diminuição de $50 \%$ no uso do papel (folhas de cadernos ou sulfites). A preocupação com a economia de recursos financeiro pela equipe gestora escolar foi pertinente, pois Viana e Camargo (2013) estudando quatro instituições públicas de ensino observou que $51 \%$ do orçamento das escolas era gasto com material de consumo, incluindo seu consumo papeleiro.

Observou nessa escola o alinhamento à chamada Economia Ecológica, que não é uma área de conhecimento recente, mas um campo transdisciplinar, pois envolve conceitos básicos de economia e ecologia. Sustenta-se na premissa de que se os agentes não atingirem os objetivos micro, não atingirão os macro. $\mathrm{O}$ conceito de sustentabilidade é não somente um objetivo no nível macro, mas o principal conceito dessa forma de economia. O desenvolvimento sustentável melhora a qualidade da vida no planeta, respeitando a capacidade de produção dos ecossistemas (Mikhailova, 2004). O desenvolvimento sustentável baseia-se na preservação do capital natural, que pode ser definido como o estoque dos recursos naturais renováveis e não renováveis, além da biomassa, onde a celulose e a produção papeleira estão incluídas. Uma parte desse capital não pode ser substituído pelo homem e dessa maneira a sustentabilidade implica em manter esse capital intocado (Constanza et al., 1998).

\section{Conclusão}

$\mathrm{Na}$ instituição educacional pesquisada constata-se uma economia monetária substancial com uma simples mudança na forma da impressão, que depende apenas do uso da impressora e de um trabalho de conscientização dos educadores da instituição.

Apesar do formato do documento e da forma de impressão são determinados pela gestão escolar, é esperado que os educadores incorporem a prática em seu cotidiano e que isso seja discutido com os alunos. Portanto, além dos impactos econômicos e educacionais, o modelo de impressão adotado alinha à instituição às preocupações ambientais atuais, além da economia de recursos financeiros.

\section{Referências}

Bonifácio, M.A.; Fiorini, P.C.; Garcia, N.N. 2016. Avaliação do impacto do consumo de papel de uma instituição de ensino superior. In: XIII Congresso Nacional de Meio Ambiente de Poços de Caldas, 2016, Poços de Caldas. Anais do XIII Congresso Nacional de Meio Ambiente de Poços de Caldas. p. 1-8.

Bortolozzi, A. 2002. Educação Ambiental e Formação Continuada: por uma abordagem socioambiental dos educadores. 2002. Ambiente \& Educação 7: 27-44.

Brasil. 1988. República Federativa do Brasil de 1988. Diário Oficial da União, Brasília, 5 de outubro de 1988. Disponível em <http://www.planalto.gov.br/ccivil_03/Constituicao/ Constituicao.htm> Acesso em 22 set. 2018.

Castro, H.F. 2009. Processos Químicos Industriais II. p. 1-30. In: Castro, H.F. Papel e celulose v.4. Universidade de São Paulo, Lorena, SP, Brasil.

Mendes, B.E.P.; Pernambuco, C.M.; Monteiro, E.M., Mata, L.U. 2013. Sistema de gestão ambiental do consumo de papel A4 e de produtos de limpeza para a Universidade Federal de Alfenas. Monografia-Universidade Federal de Alfenas, Alfenas, MG, Brasil.

Mikhailova, I. 2004. Sustentabilidade: evolução dos conceitos teóricos e os problemas da mensuração prática. Revista Economia e Desenvolvimento, 16: 22-41.

Moraes, G.H.S.M.; Cappellozza, A.; Meirelles, F.S. Será o fim do papel? Os avanços tecnológicos e seus possíveis impactos no consumo de papel. Internext-Revista Eletrônica de Negócios Internacionais da ESPM, 2: 48-65.

Secretaria de Educação do Matogrosso. 2009. Caminhos que podem levar a sua escola ao caminho da sustentabilidade ambiental. Disponível em: <http://http:www.seduc.mt.gov. br/>. Acesso em: 17 dez. 2017.

Siqueira, R.M.; Paranhos, U.; Rodrigues, R.A.; Silva, E.C.C. 2018. Lean Office: estudo de caso no setor público de São Paulo. Braziliain Journal of Development. 5: 2150-2162.

Tauchen, J.; Brandli, L. L. 2006. A gestão ambiental em instituições de ensino superior: modelo para implantação em campus universitário. Gestão \& Produção, 3: 503-515.

Teixeira, A.C. 2007. Educação ambiental: caminho para a sustentabilidade. Revista Brasileira de Educação Ambiental, 2: 21-29.

Teixeira, R.S.; Souza, R.O.L.; Vasconcellos, C.A.B. 2015. Percepção de alunos de escolas públicas sobre reciclagem: ferramentas de iniciação à educação ambiental. Revista do Centro de Ciências Naturais e Exatas - UFSM, 2: 11741182.

Viana, M.P.; Camargo, R.B. 2013. Gestão financeira escolar: um estudo sobre os programas de transferência de recursos financeiros. In: XXVI Simpósio Brasileiro de Política e Administração Escolar, 2013, Recife. Anais do XXVI Simpósio Brasileiro de Política e Administração Escolar. p. 1-20

The Economist. 2012. How much paper does a person use on average in a year?. Disponível em: <http://www.economist. com/blogs/graphicdetail/2012/04/daily-chart-0>. Acesso em: 30 mar. 2017. 